\title{
Structural Elucidation of two Compounds from the Fruit of Medicinally Important Plant, Basella rubra
}

\section{SWARNALI NATH CHOUDHURY ${ }^{1 *}$, BIPLAB DE ${ }^{2}$ and SATYA BHUSAN PAUL ${ }^{3}$}

1Department of Science And Technology, ICFAI University Tripura,

Kamalghat, Agartala, Tripura - 799210, India.

${ }^{2}$ Regional Institute of Pharmaceutical Science And Technology, Abhoynagar, Agartala, Tripura, India.

${ }^{3}$ Department of Chemistry, Assam University, Dargakona, Silchar, Assam, India.

${ }^{*}$ Corresponding author: Email : schoudhury123@gmail.com

http://dx.doi.org/10.13005/ojc/320183

(Received: December 21, 2015; Accepted: March 03, 2016)

\begin{abstract}
Basella rubra is a medicinal plant species found in India and other parts of Asia and tropical Africa. It improves the appetite, useful in biliousness, leprosy, dysentery, ulcers and it has antiviral and antipyretic activity. The red pigment from the fruit has good colouring ability. It is bright purple at $\mathrm{pH}$ 3-7. It is a good additive and a safe, non-poisonous colorant. At present, the dyestuff industry has grown rapidly because of the vital role played by small - scale sector, which is responsible for the production of azo, acids, basics and direct dyes. But such synthetic dyes have toxic effect and hence may not be useful in edible substances. Therefore keeping this in mind the structure of two separated compounds from the fruit pigment of medicinally important plant Besella rubra were elucidated. The structures of the compounds have been characterized on the basis of spectral data such as IR, ${ }^{1} \mathrm{H}$ NMR, ${ }^{13} \mathrm{C}$ NMR and Mass spectral studies.
\end{abstract}

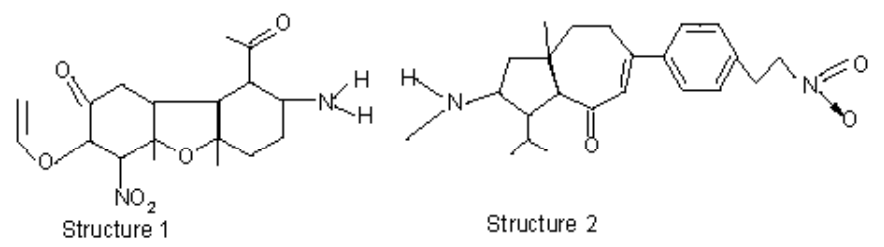

Key words: Basella rubra, fruit, solvent extraction, pigment, structure elucidation.

\section{INTRODUCTION}

Nature has supplied beautiful varieties of natural products, both useful and harmful. Scientific studies are usually carried out to assess the efficacy of medicinal plants, which are already known to have some therapeutic value in the treatment of diseases. Very little reports on isolation and utilization 
of pigment extracted from natural products are published. Hu et. al ${ }^{1}$ could extract a red pigment from natural mulberry. As it was found to be nonpoisonous in nature at the same time had good stability to light and heat, the red pigment extracted from natural mulberry was used as an additive in candy, beverages, fruit wine jelly, ice cream etc. The yellow pigment of Gardenia from the fruit of $G$. Jasmonoides, extracted by Lui, Wei and Sheng'2, was found to be bright, stable, safe and had strong coloning ability. It can thus be used as a colouring agent for the food industry. At present the dye stuff industry represents the highest development of chemical technology ${ }^{3}$.

Basella rubra is a medicinal plant species found in India and other parts of Asia and tropical Africa. The juice of leaves improves the appetite, useful in biliousness, leprosy, dysentery, ulcers and it has antiviral and antipyretic activity ${ }^{4}$. It also improves the voice and applied to burns. Leaves yield â-carotene in large amount and á- carotene in small amounts and traces of other carotenoids ${ }^{5}$, Pro-vitamin $A^{6,7}$, Lipids, amino acids, protein ${ }^{8,9}$ and ascorbic acid ${ }^{10}$, Cao et. $\mathrm{al}^{11}$ extracted a red pigment from the fruit of Basella rubra which has good colouring ability. It is bright purple at $\mathrm{pH} 3-7$. It is a good additive and a safe, non-poisonous colorant. It is decomposed under the effect of light, heat and in presence of metal ions such as $\mathrm{Fe}^{2+}, \mathrm{Fe}^{3+}, \mathrm{Cu}^{2+}$.

Purified Basella rubra fruit's red pigment gave the characteristic absorption of â- cyanins and betanin. Therefore compounds from the fruits of Basella rubra might have some medical activity and also some colouring ability. With such curiousness compounds were extracted from the fruits of Basella rubra and their structures were elucidated.

\section{RESULTS AND DISCUSSION}

The isolated compounds after purification were found to be in semi solid state.

$\mathrm{SN}_{1}$ is red in colour and soluble in water. Lessaignes' procedure confirmed the presence of $\mathrm{N}$ and absence of $\mathrm{S}$ and halogens in the isolated compound. The compound is an organic ketotherial compound with a primary amino group and nitro group. Being a Ketonic compound it contains $\mathrm{C}, \mathrm{H}$ and $\mathrm{O}$ as elements. Further preliminary analysis confirmed the compound to be unsaturated and aliphatic in nature.

In the IR spectral studies of $\mathrm{SN}_{1}$ in $\mathrm{KBr}$ pelletes, the peak at $1622.6 \mathrm{~cm}^{-1}$ can be assigned to $>\mathrm{C}=\mathrm{O}$ stretching due to the keto group. The peak at $1312.66 \mathrm{~cm}^{-1}$ and at $1253.52 \mathrm{~cm}^{-1}$ can be correlated to the symmetrical and asymmetrical stretching of the (C-O-C) group. The peak at $3421.18 \mathrm{~cm}^{-1}$ and $3276.17 \mathrm{~cm}^{1}$ is due to the presence of primary amine $\left(-\mathrm{NH}_{2}\right)$ group. The peak at $1394.33 \mathrm{~cm}^{-1}$ shows the presence of nitro group $\left(-\mathrm{NO}_{2}\right)$. The three peaks at $2954.99 \mathrm{~cm}^{-1}, 2946.81 \mathrm{~cm}^{-1}$ and $2846.81 \mathrm{~cm}^{-1}$ are due to the presence of methyl $(-\mathrm{C}-\mathrm{H})$ protons.

In the ${ }^{1} \mathrm{H}$ NMR spectral analysis signals near $\delta 4$ (doublet) is for amino protons. Peaks at $\delta 2.84126,2.82404,2.82096$ (multiplet) is due to methylene protons $\left({ }^{4} \mathrm{C},{ }^{8} \mathrm{C},{ }^{5} \mathrm{C},{ }^{6} \mathrm{C}\right)$.

In the ${ }^{13} \mathrm{C}$ NMR spectra, the peak around 177.364 is due to the carbonyl group $\left({ }^{3} \mathrm{C}\right)$. The peak at $\delta 180.364$ is due to the presence of free carbonyl group $\left({ }^{7} \mathrm{C}\right)$. The peaks at $\delta 98.195$ and 96 , is due to terminal double bond $\left({ }^{7} \mathrm{C},{ }^{8} \mathrm{C}\right)$. Peaks around $\delta 80$, 76,75 are due to quarternary carbon atoms $\left({ }^{4} \mathrm{C},{ }^{6} \mathrm{C}\right)$. Peaks at $\delta 44,41$ are due to secondary carbon atom $\left({ }^{5} \mathrm{C},{ }^{6} \mathrm{C}\right)$.

In mass spectral analysis the compound showed a molecular ion peak $(M+1)^{+}$at $\mathrm{m} / \mathrm{z} 368$.

A peak was recorded as $\mathrm{m} / \mathrm{z} 30$ for $\mathrm{NO}^{+}$ and hence formation of compound having $\mathrm{m} / \mathrm{z} 337$ showing most intensity (base peak).

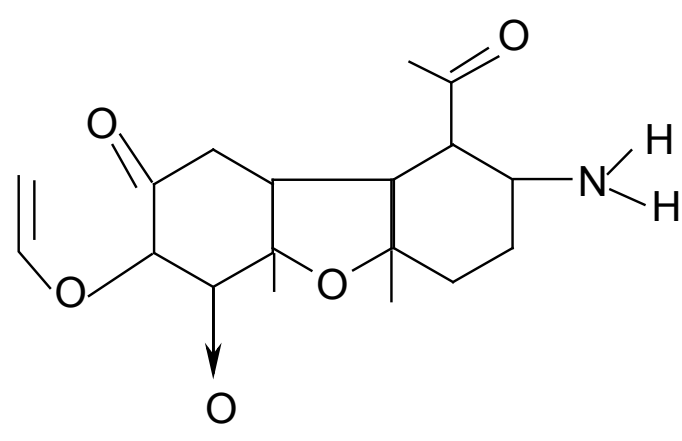

$\mathrm{m} / \mathrm{z}=337$

The other fragments $(\mathrm{m} / \mathrm{z})+$ obtained may be described as under- 
<smiles>C=COC1C(=O)CC2C1OC1(C)CCC(NC)CC21</smiles>

$M+1=253$<smiles>C=COC1C(=O)CC2C=C(C)OC21C</smiles>

$M+1=196$<smiles>[NH]NC1CCC(=O)CC1</smiles>

$M+1=114$

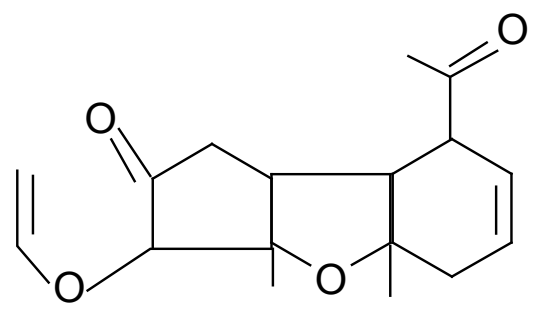

$M+1=292$

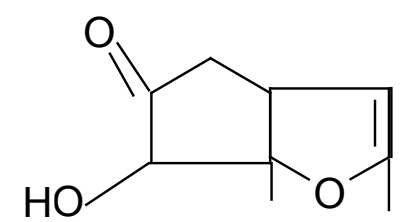

$M+1=170$

Based on the above spectral analysis the structure may be drawn as-

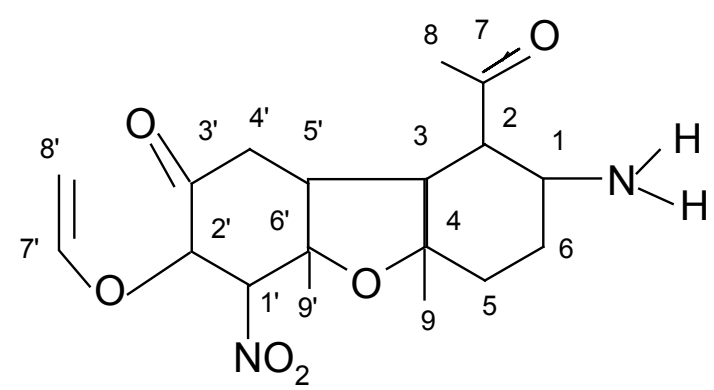

Structure 1

$\mathrm{SN}_{2}$ is deep green in colour and soluble in $\mathrm{CHCl}_{3}$. Lessaignes' procedure confirmed the presence of $\mathrm{N}$ and absence of $\mathrm{S}$ and halogens in the isolated compound. The compound is an organic keto $(>\mathrm{C}=\mathrm{O})$ compound with a secondary amino group and nitro group. Being a ketonic compound it contains $\mathrm{C}, \mathrm{H}$ and $\mathrm{O}$ as elements. Further preliminary analysis confirmed the compound to be unsaturated and aromatic in nature.

In the IR spectral studies in $\mathrm{KBr}$ pelletes, the peak at $1746 \mathrm{~cm}^{-1}$ can be assigned to $>\mathrm{C}=\mathrm{O}$ stretching due to the keto group. The peak at 1375 $\mathrm{cm}^{-1}$ shows the presence of nitro group $\left(-\mathrm{NO}_{2}\right)$. The peak at $1262.25 \mathrm{~cm}^{-1}$ is due to the stretching of $-\mathrm{N}=\mathrm{O}$ group. The three peak at $2958 \mathrm{~cm}^{-1}, 2925$ $\mathrm{cm}^{-1}$ and $2853 \mathrm{~cm}^{-1}$ are due to the presence of methyl (-C-H) stretching. The peak at $1459 \mathrm{~cm}^{-1}$ shows the presence of aromatic $\mathrm{C}-\mathrm{C}$ stretching.

In the ${ }^{1} \mathrm{H}$ NMR spectral analysis signals near $\delta 7$ (multiplet) is for phenyl protons. The peaks around $\delta 4.1$ (doublet) is due to the presence of $\mathrm{N}-\mathrm{H}$ $(1 \mathrm{H}$, upfield) and due to the presence of $\mathrm{HC}=\mathrm{CH}$ protons $\left(1 \mathrm{H}\right.$, upfield $\left.{ }^{7} \mathrm{C}-{ }^{8} \mathrm{C}\right)$.

In the ${ }^{13} \mathrm{C}$ NMR spectra, the peak at $\delta 173$ is due to the presence of $>\mathrm{C}=\mathrm{O}$ group. The peak at $\delta 130$ is due to the presence of aromatic carbon atom. The peak around $\delta 77$ shows presence of quaternary carbon atoms $\left({ }^{11} \mathrm{C},{ }^{7} \mathrm{C},{ }^{4} \mathrm{C},{ }^{1} \mathrm{C}\right)$. The peak around $\delta 68$ is due to the presence of tertiary carbon atom $\left({ }^{17} \mathrm{C},{ }^{18} \mathrm{C}\right)$. The peaks around ä 38 and 28 shows the presence of secondary $\left({ }^{12} \mathrm{C},{ }^{13} \mathrm{C}\right)$ and primary carbon atom $\left({ }^{19} \mathrm{C},{ }^{20} \mathrm{C}\right)$ respectively. The peaks at $\delta 14.120$ is due to the presence of terminal methyl group $\left({ }^{21} \mathrm{C}\right)$

In mass spectral analysis the compound showed a molecular ion peak $(\mathrm{M}+1)^{+}$at $\mathrm{m} / \mathrm{z} 382$.

The base peak was recorded as $\mathrm{m} / \mathrm{z} 337$ due to elimination of $\mathrm{NO}_{2}$<smiles>CCc1ccc(C2=CC(=O)C3C(C(C)C)C(NC)CC3(C)CC2)cc1</smiles> 
$\mathrm{M}+1=337$

The other fragments $(\mathrm{m} / \mathrm{z})+$ obtained may be described as under-<smiles>CNC1CC2(C)CCC(c3ccccc3)=CC(=O)C2C1C(C)C</smiles>

$M+1=310$<smiles>CNC1CC2(C)CCC(c3ccc(CCC=O)cc3)=CC(=O)C2C1C(C)C</smiles>

$M+1=356$

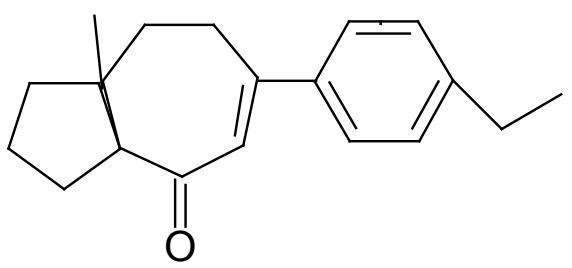

$M+1=255$

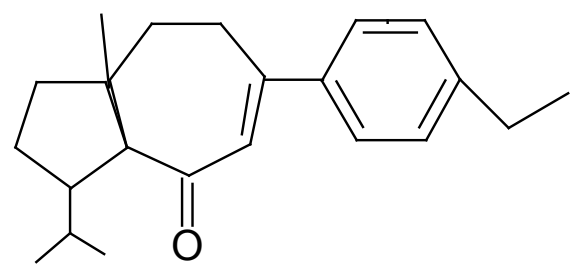

$\mathrm{M}+1=307$

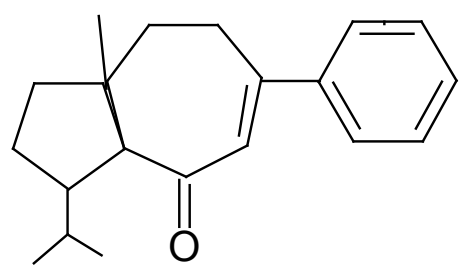

$M+1=280$

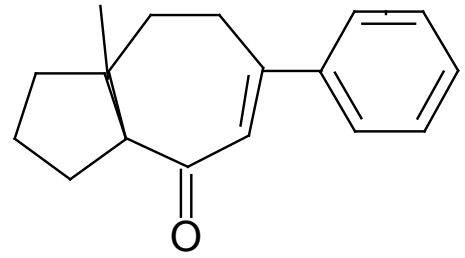

$M+1=237$

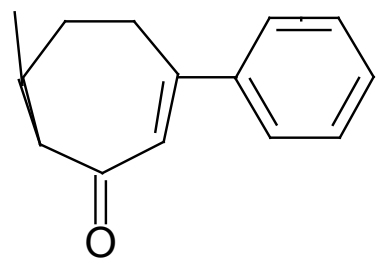

$M+1=195$

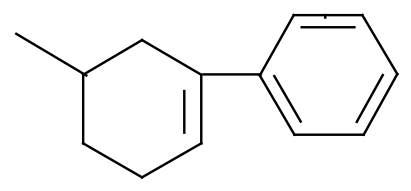

$M+1=167$

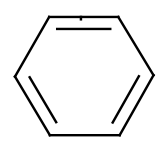

$\mathrm{M}+1=84$

Based on the above spectral analysis the structure may be drawn as-

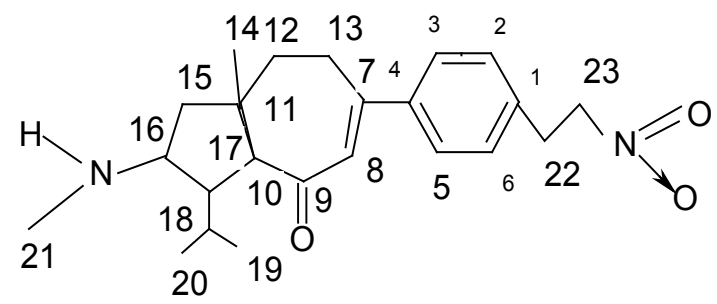

Structure - 2 


\section{MATERIALS AND METHODS}

\section{Chemicals used}

All the chemicals used were of analytical grade. The solvents acetone, methanol and petroleum ether were utilized of Qualigens Fine Chemicals, Mumbai, India. Silica gel G used for TLC, nitric acid and ethyl acetate were purchased of Bengal Chemicals and Pharmaceuticals Ltd. The solvents used for extraction and chromatography were distilled at their boiling points.

\section{Collection of Sample}

The fruits of Basella rubra were collected from Agartala in the month of May 2013 and authenticated accordingly.

\section{Sample Preparation}

The fresh fruits of the herb were extracted in a solvent mixture [methanol and ethyl acetate $(1: 2)]$ in a soxhlet apparatus by taking $100 \mathrm{~g}$ of fruit in $150 \mathrm{ml}$ of solvent mixture. The methanol part was red (lower layer) in colour and the ethyl acetate part was greenish yellow (upper layer).

\section{Separation}

The two layers were separated using a separating funnel and distilled and concentrated in vacuum. The ethyl acetate part gave a greenish compound and methanol part gave a red compound.
TLC was carried out using Silica gel $G$ as stationary phase and $\mathrm{CCl}_{4}$ and $\mathrm{CHCl}_{3}$ (1:1 ratio) as mobile phase. By TLC study pure compounds were separated and characterized as - Methanol (red) extract on TLC showed a single spot and Ethyl acetate (green part) extract spotted by two spots. Hence, little chloroform was added to the Ethyl acetate (green part) extract. Immediately it formed two parts - a red oily part in ethyl acetate (named as $\mathrm{SN}_{1}$ ) and a green part in chloroform (named as $\mathrm{SN}_{2}$ ). Methanol (red) extract material and $\mathrm{SN}_{1}$-both showed same $\mathrm{R}_{\mathrm{f}}$ value in TLC, These were concentrated again and were studied further by TLC, which showed that both the parts contained single compound each.

\section{Experimental Section}

The I.R. spectra were recorded in FTIR 1.50SU Shimadzu Spectrophotometer, in $\mathrm{KBr}$ pellets. ${ }^{1} \mathrm{H},{ }^{13} \mathrm{C}$ - NMR were run on Mercury- 400BB, in $\mathrm{CDCl}_{3}$, while mass spectra was performed in Agilent 7890 GC coupled with 5975 MS.

\section{CONCLUSION}

Basella rubra is a medicinal plant. It improves the appetite, useful in biliousness, leprosy, dysentery, ulcers and it has antiviral and antipyretic activity. The structures of two separated compounds from the fruit pigment were elucidated.<smiles>C=COC1C(=O)CC2C3C(C(C)=O)C(NC)CCC3(C)OC12[N+](=O)[O-]</smiles>

Structure 1<smiles></smiles>

Structure 2

\section{REFERENCES}

1. Hu L, Tang Z, Ye Q, He M, Mao C, Wu Y and Lin L, Chem Abs, 1991, 115, 862.

2. Liu S, Wei S and Sheng S, Chem Abs, 1991, 115, 862.

3. Sharma B K, Industrial chemistry including chemical Engineering, Goel Publishing House, Meerut, 1995, 7th edition, 839-840.
4. Tanigguchi T, Chemical Abs, 1978, 88, 78.

5. Penteado, M D V C, Minazzi R S, Regina S and Bicuda D A L, Chem Abs, 1987, 107, 609.

6. Shimizu T and Mori M, Chem Abs, 1981, 95, 433.

7. Hasotani K, Hirata N and Matoba T, Chem 
Abs, 1989, 111, 518.

8. Hall NT, Nagy S and Robert E, Proc Fla State Hortic Soc, 1976, 88, 486-90,

9. Haque T, Bhuiya A Hand Ahmad K, Bangladesh J Biol Sci, 1976, 5(1), 31-4.
10. Caldwell M and Gim-Sai Y, Ecol Food Nutr, 1973, 2(1), 35-8.

11. Cao $Y$, Hu L, Tang $Z$ and $Y e ~ Q$, Chem Abs, 1991, 115, 862. 